\title{
Secular trends in the initiation of therapy in secondary fracture prevention in Europe: a multi-national cohort study including data from Denmark, Catalonia, and the United Kingdom
}

\author{
M. K. Skjødt ${ }^{1,2,3}$ - S. Khalid ${ }^{4}$ - M. Ernst ${ }^{3,5} \cdot$ K. H. Rubin ${ }^{3}$ - D. Martinez-Laguna ${ }^{6,7,8} \cdot$ A. Delmestri $^{4}$ - M. K. Javaid ${ }^{4}$.

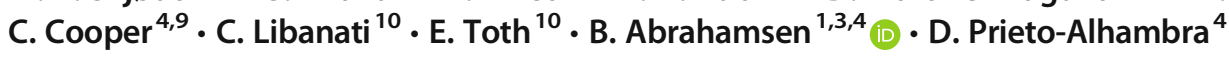

Received: 27 November 2019 / Accepted: 18 February 2020 / Published online: 17 March 2020

(C) The Author(s) 2020

\begin{abstract}
Summary This paper demonstrates a large post-fracture anti-osteoporosis treatment gap in the period 2005 to 2015 . The gap was stable in Denmark at around 88-90\%, increased in Catalonia from 80 to $88 \%$, and started to increase in the UK towards the end of our study. Improved post-fracture care is needed.

Introduction Patients experiencing a fragility fracture are at high risk of subsequent fractures, particularly within the first 2 years after the fracture. Previous studies have demonstrated that only a small proportion of fracture patients initiate therapy with an antiosteoporotic medication (AOM), despite the proven fracture risk reduction of such therapies. The aim of this paper is to evaluate the changes in this post-fracture treatment gap across three different countries from 2005 to 2015.

Methods This analysis, which is part of a multinational cohort study, included men and women, aged 50 years or older, sustaining a first incident fragility fracture. Using routinely collected patient data from three administrative health databases covering Catalonia, Denmark, and the United Kingdom, we estimated the treatment gap as the proportion of patients not treated with AOM within 1 year of their first incident fracture.

Results A total of 648,369 fracture patients were included. Mean age 70.2-78.9 years; $22.2-31.7 \%$ were men. In Denmark, the treatment gap was stable at approximately $88-90 \%$ throughout the 2005 to 2015 time period. In Catalonia, the treatment gap increased from 80 to $88 \%$. In the UK, an initially decreasing treatment gap - though never smaller than $63 \%$ - was replaced by an increasing gap towards the end of our study. The gap was more pronounced in men than in women.

Conclusion Despite repeated calls for improved secondary fracture prevention, an unacceptably large treatment gap remains, with time trends indicating that the problem may be getting worse in recent years.
\end{abstract}

Keywords Fracture prevention $\cdot$ Health Services Research

M. K. Skjødt and S. Khalid are joint first authors.

Electronic supplementary material The online version of this article (https://doi.org/10.1007/s00198-020-05358-4) contains supplementary material, which is available to authorized users.

B. Abrahamsen

b.abrahamsen@physician.dk

1 Department of Medicine, Hospital of Holbaek, Holbaek, Region Zealand, Denmark

2 Department of Medicine, Hospital of Slagelse, Slagelse, Region Zealand, Denmark

3 OPEN, Open Patient data Explorative Network, Odense University Hospital, Odense, Denmark

4 Nuffield Orthopaedic Centre, Oxford University Hospitals, Oxford, England
5 Department of Public Health, Clinical Pharmacology and Pharmacy, University of Southern Denmark, Odense, Denmark

6 GREMPAL Research Group, Fundació Institut Universitari per a la recerca a l'Atenció Primària de Salut Jordi Gol i Gurina (IDIAPJGol), CIBERFES, Barcelona, Spain

7 Universitat Autònoma de Barcelona, Bellaterra (Cerdanyola del Vallès), Spain

8 Atenció Primària Barcelona Ciutat, Institut Català de la Salut, Barcelona, Spain

9 MRC Lifecourse Epidemiology Unit, University of Southampton, Southampton General Hospital, Southampton, England

10 UCB Pharma, Anderlecht, Belgium 


\section{Introduction}

Osteoporosis is defined by microarchitectural changes of the bone and reduced bone mass, causing an increased bone fragility and an increased risk of fractures. Low-energy fragility fractures are the clinical consequence of osteoporosis. In 2010, 27.6 million women and men in the European Union were estimated to have osteoporosis, equivalent to a prevalence of $5.5 \%$ of the population. In the same year, a total of 3.5 million fragility fractures were sustained. Of these, 600,000 were hip fractures, 500,000 were clinical vertebral fractures, 600,000 were forearm fractures, and 1.8 million fractures were categorized as "other" [1].

The presence of fragility fractures, irrespective of fracture location, has been demonstrated to be indicative of a doubling of the risk of a subsequent fracture [2,3]. Depending on the location of this initial fracture, a relative risk of subsequent fractures of 1.4 to 19.0 as compared with those without fractures has been demonstrated in prior studies [2]. The risk of subsequent fractures is highest in the first 2 years after a fracture, then decreasing over time [4]. Therapy with antiosteoporosis medications (AOM) is effective in preventing subsequent fragility fractures. Accordingly, three Cochrane reviews have confirmed the effectiveness of oral bisphosphonates in secondary prevention of osteoporotic fractures in general [5-7]. In addition, clinical trials in patients with an osteoporotic fracture have demonstrated the significant risk reduction of subsequent fractures with other AOM, including zoledronic acid, denosumab, teriparatide, raloxifene, and strontium ranelate [8-13]. In line with these findings, national and international guidelines recommend either assessment of osteoporosis or initiation of pharmacological secondary fracture prevention-depending on guideline and fracture location - in patients who sustain a fragility fracture, unless exceptional circumstances exist [14-18].

Despite such evidence-based recommendations, a significant post-fracture treatment gap is known to prevail across healthcare systems and settings [19-28]. Several publications report that in some countries as few as $10-20 \%$ of patients with fragility fractures go on to receive AOM [23-27], with this gap being more pronounced in men as well as in the elderly $[20,26,29]$. Despite the attention given to the importance of closing the treatment gap, long-term time trends seem to indicate that the gap has even been increasing in recent years $[25,26]$.

Because the treatment gap is strongly affected by changing healthcare resources and medical practices, comparative and longitudinal time series analyses are needed to monitor secondary fracture prevention and to understand how structural healthcare changes may affect this. However, few analyses are long-term, and most often they present only a national perspective. The aim of this paper is to evaluate the changes in the anti-osteoporosis treatment gap in secondary fracture prevention in Denmark, the UK, and Catalonia from 2005 (2007 for the latter) to 2015 .

\section{Methods}

This analysis forms part of the Multinational Observational Database Study on Imminent Osteoporotic Fracture Risk (the IFRISK study), an observational cohort study evaluating patient characteristics and 1- and 2-year fracture rates in patients at high risk of osteoporotic fractures. This ongoing study uses routinely collected health data obtained from three European administrative health databases. The present work is a cohort analysis of patients with a first incident osteoporotic fracture in order to examine the changes in the antiosteoporosis treatment gap in the three countries from 2005 to 2015. The osteoporosis treatment gap is defined as the proportion of patients not treated with AOM within 1 year following their index fracture.

\section{Population}

Eligible patients were men and women, aged 50 years or older, with a first incident (= index) fracture at any site except face, skull, and digits, as fractures at these sites are generally considered non-osteoporotic. If within the 6 months prior to the incident fracture, a fracture had been coded at the same anatomical site as the incident fracture, the incident fracture would be considered a repeat admission for the original fracture rather than a first fracture. Patients had to be registered in one of the national health registries at least 1 year prior to their index fracture. We pre-specified exclusion of patients with Paget's disease, a history of breast or prostate cancer, or a history of bone metastasis. Additionally, CPRD and SIDIAP general practices with a lack of linkage to hospital admissions/ records were excluded to maximize the quality and completeness of the analytical dataset.

\section{Data sources}

We extracted patient-level data on the index fracture along with baseline demographic, clinical, socioeconomic, and medication information from the following registries:

- Clinical Practice Research Datalink (CPRD) GOLD, which comprises data from primary care linked to hospital and outpatient data (secondary care), including data on demography and medication, from over 7 million patients in the UK.

- Sistema d'Informació per al Desenvolupament de la Investigació en Atenció Primària (SIDIAP), which represents more than 6 million people in Catalonia (Spain) and is based on primary care records linked to pharmacy 
dispensations and hospital inpatient data. Data from SIDIAP is available from 1st January 2006, a date considered of standard and established use of electronic medical records in Catalonia.

- Danish Health Registries (DHR), including the National Prescriptions Database (which contains data on all filled prescriptions since 1995), the National Patient Registry (which contains diagnosis codes and treatments for all patients since 1977 for hospitals and since 1995 for outpatient clinics), and the National Cause of Death register (which includes date and cause(s) of death). These registers cover the entire Danish population until death or emigration.

\section{Study period}

Baseline was defined as the date of the index fracture. The baseline period (i.e. the lookback or "window" period) to identify baseline demographic, clinical, and socioeconomic characteristics was defined as the 12 months leading up to the index fracture. The exception was medical history (cancer, cardiovascular disease, diabetes, arthritis, liver disease, dementia, neurological conditions, asthma or chronic obstructive pulmonary disease, chronic kidney disease, endocrine disease, and malabsorption), for which no limitations in the length of the lookback period was applied.

Follow-up data included treatment with AOM within 1 year of the index fracture, defined as any use of bisphosphonates, teriparatide, denosumab, strontium ranelate, or raloxifene. For SIDIAP and DHR, treatment was characterized by pharmacy dispensation of AOM, while for the CPRD, it was characterized by AOM prescription. These differences were due to the content of the data sources. Data was collected for patients with an index fracture between 2005 (2007 for SIDIAP) and 2015.

The study protocol was approved by the ISAC ethics committee for use of CPRD data, by the SIDIAP Scientific and Ethics Committee, and for the use of the Danish Health Registries by the Danish Medicines Agency, the Danish Data Protection Agency, and Statistics Denmark.

\section{Statistical analysis}

The three databases were curated using a bespoke (protocolbased) common data model and code lists. A single script (written in $\mathrm{R}$ version 3.3.2) was used for the analysis, which was run independently on each database. For each database, we summarized the baseline characteristics (both demographic and clinical) descriptively. Continuous variables were summarized using mean and standard deviation, while categorical variables were summarized by the number and/or proportion of participants.
Data was censored at the first occurrence after the index date of either an additional osteoporotic fracture, death or migration, or 1 year after the date of the index fracture. All analyses were stratified according to fracture location and year of fracture. In an additional analysis, we further stratified the data according to gender. In the presentation of the data, we pooled the data into 4 distinct time periods for smoothening (2005-07, 2008-10, 2011-13, and 2014-15, respectively).

\section{Results}

A total of 1,282,991 patients were eligible for the study. After the pre-specified exclusion of patients less than 50 years old at the time of the index fracture $(n=602,167)$, those with an index date after 31st December $2015(n=7862)$, those with a history of Paget's disease $(n=358)$, breast or prostate cancer $(n=23,668)$, and/or bone metastasis $(n=691),{ }^{1}$ a total of 648,369 fracture patients were included in this study. Of these, 83,514 were recorded in CPRD (UK), 55,304 in SIDIAP (Catalonia), and 509,551 in DHR (Denmark). Table 1 shows the baseline characteristics of each of these sub-cohorts. At baseline, the groups differed significantly on several characteristics. Notably, the participants from the UK were older (mean age 78.9 years), one in five was male, and more had a history of cancer $(8.9 \%)$ or chronic kidney disease (11.9\%). In comparison, the Danish cohort were younger (mean age 70.8 years), one in three was male, and they had the lowest Charlson Comorbidity Index (CCI) score $(86.4 \%$ had a CCI of $0)$. The Catalan cohort were relatively comparable with the Danish, yet had the highest CCI score $(>26 \%$ had a CCI of 2 or more), also exceeding that of the UK population. Interestingly, the number of participants on steroids in the past year was comparable between the three countries, irrespective of the differences in age and CCI score. Prevalent use of antiosteoporosis medication at baseline was highest in Catalonia (10.3\%) followed by the UK $(9.2 \%)$, while the use in Denmark was substantially lower (4.8\%).

\section{Treatment gap: general trend}

Figure 1 shows the treatment gap across all fracture locations for the UK, Catalonia, and Denmark from 2005 to 2015 (Catalonia from 2007). The treatment gap was largest in Denmark, and remained stable over the study period at 88-90\%. In comparison, the treatment gap was lowest in the UK at the starting point in 2005-07 and demonstrated a decreasing trend during the two subsequent time periods. In 2011-13, 37\% of all patients aged 50 years or older and presenting with a first fracture were treated with antiosteoporosis medication within 1 year (i.e. a treatment

\footnotetext{
${ }^{1}$ Please note that groups are not mutually exclusive
} 
Table 1 Baseline characteristics

\begin{tabular}{|c|c|c|c|}
\hline & CPRD & SIDIAP & DHR \\
\hline$N$ & 83,514 & 55,304 & 509,551 \\
\hline Age, years (mean (SD)) & $78.9(11.2)$ & $70.2(13.7)$ & $70.8(12.4)$ \\
\hline Sex, male $(\%)$ & 22.2 & 31.7 & 30.9 \\
\hline BMI; kg/m² (mean (SD)) & $25.0(5.5)$ & $28.9(5.2)$ & N/A \\
\hline \multicolumn{4}{|l|}{ Medical history (\%) } \\
\hline Cancer & 8.9 & 5.9 & 7.0 \\
\hline COPD & 5.8 & 5.9 & 5.3 \\
\hline IHD & 2.8 & N/A & 4.2 \\
\hline CKD & 11.9 & 7.3 & 1.2 \\
\hline \multicolumn{4}{|l|}{ Charlson comorbidity index $(\%)$} \\
\hline 0 & 59.2 & 48.5 & 86.4 \\
\hline 1 & 18.1 & 24.9 & 7.9 \\
\hline 2 & 10.8 & 13.3 & 3.6 \\
\hline 3 & 6.4 & 6.8 & 1.1 \\
\hline$\geq 4$ & 5.5 & 6.5 & 1.1 \\
\hline Steroid use in previous year ${ }^{*}(\%)$ & 7.8 & 8.2 & 8.3 \\
\hline PPI use in previous year $(\%)$ & 23.0 & 48.9 & 14.5 \\
\hline Anti-osteoporosis medication in previous year ${ }^{\dagger}(\%)$ & 9.2 & 10.3 & 4.8 \\
\hline
\end{tabular}

$B M I$ body mass index, $C K D$ chronic kidney disease, $C O P D$ chronic obstructive pulmonary disease, $I H D$ ischaemic heart disease, $N / A$ not available, $P P I$ proton pump inhibitor

* Steroid use is defined as filled prescriptions of a glucocorticoid at a total dose equivalent to $\geq 450 \mathrm{mg}$ prednisolone during the baseline period

${ }^{\dagger}$ Anti-osteoporosis medication includes bisphosphonates, teriparatide, denosumab, raloxifene, and strontium ranelate and for SIDIAP also bazedoxifene

gap of $63 \%)$. In the last time period (2014-15), the treatment gap in the UK increased again but still remained lower than that seen in 2005-07. In Catalonia, the treatment gap was at $80 \%$ in 2007 and has been increasing since the 2008-10 time period and until the end of this study, at which point it was around $88 \%$. Overall, within each country, the trends for individual fracture sites were similar to those seen for all fractures. Details regarding the treatment
Fig. 1 The treatment gap for all fractures across the United Kingdom, Catalonia and Denmark. The treatment gap is given as the proportion of patients not treated with AOM within 1 year following their index fracture

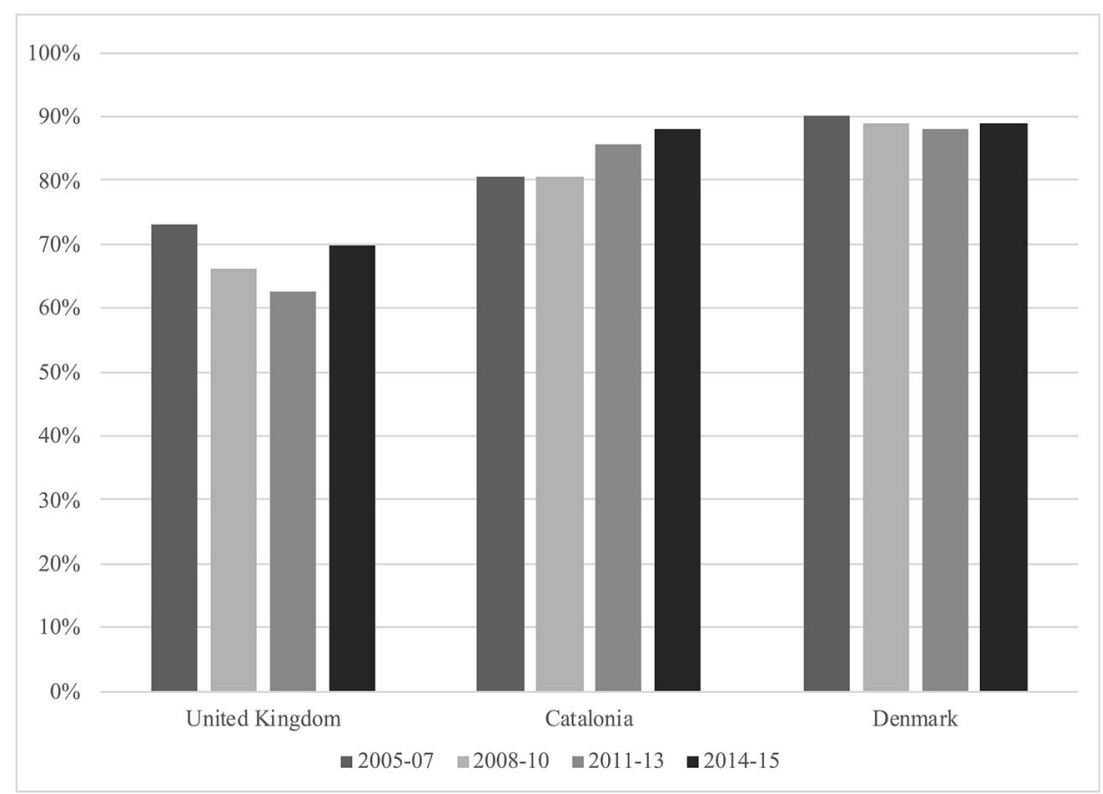


gaps can be found in Figs. 1, 2, 3, 4, and 5 and supplementary Tables 1, 2, 3 .

\section{The United Kingdom}

Figure 2 shows the treatment gap in the UK from 2005-07 to 2014-15, stratified according to fracture location. As described above, the treatment gap diminished from 2005-07 to 2011-13 then started to increase again. As is seen in Fig. 2, this was a general tendency across fracture locations. Secondary prevention among hip fracture patients was better than average throughout the study period.

\section{Catalonia}

As demonstrated in Fig. 3, the treatment gap in Catalonia increased from the 2008-10 time period and throughout the study across all fracture locations. Like in the UK, the secondary prevention among hip fracture patients was marginally better than average. Interestingly, secondary prevention among patients with spine fractures was remarkably better, yet the treatment gap still increased over time.

\section{Denmark}

The treatment gap in Denmark was stable throughout the study period, as is seen in Fig. 4. This was remarkably similar across fracture locations, with only minor deviations across the time periods. As in Catalonia, the treatment gap among hip fracture patients was smaller than average yet even smaller for spine fracture patients. The treatment gap among patients with spine fractures demonstrated an increasing trend towards the end of this study.

Fig. 2 The treatment gap in the United Kingdom stratified according to fracture location (all, hip, spine, non hip non spine, and wrist fractures, respectively) and time period

\section{Treatment gap: gender discrepancies}

Figure 5 demonstrates the treatment gap across the three databases stratified according to gender for all, hip, and spine fractures, respectively. Across the UK, Catalonia, and Denmark, a similar trend of a larger treatment gap in men than in women was observed, irrespective of fracture location. The trend for non hip, non spine fractures and wrist fractures was similar (data on file). We did not observe any consistent changes in the gender difference over the years.

\section{Discussion}

This analysis shows the presence of very significant treatment gaps in the secondary fracture prevention across three European countries but with some differences between the countries. In the UK, the treatment gap was $63-73 \%$ during the study period; in Catalonia, it was $80-88 \%$; and in Denmark, it was stable at 88-90\%. Although the UK exhibited a narrowing treatment gap in the first years of our analysis, as well as an overall reduction in the treatment gap from 2005 to 2015 , a trend towards an increase is noted towards the end of the study period. In Denmark, the gap was large and stable during the analysis, and in Catalonia, the treatment gap showed an increasing overall trend since the 2008-10 time period. Across the three countries, the treatment gap was consistently larger in men than in women.

The results of our analysis are in line with other studies on secondary fracture prevention, which have demonstrated significant treatment gaps across healthcare systems and settings [19-26, 28, 30]. While many such studies are based in North America [19-22, 25, 26, 28], our study along with several

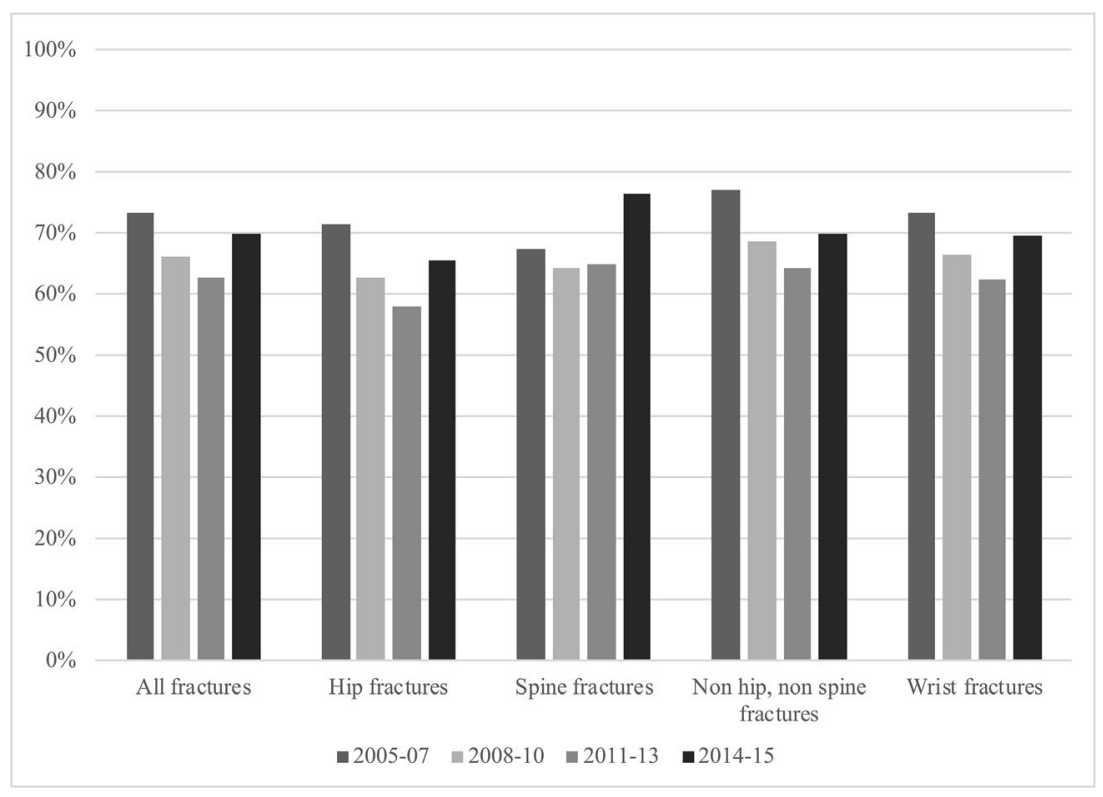


Fig. 3 The treatment gap in Catalonia stratified according to fracture location (all, hip, spine, non hip non spine, and wrist fractures, respectively) and time period

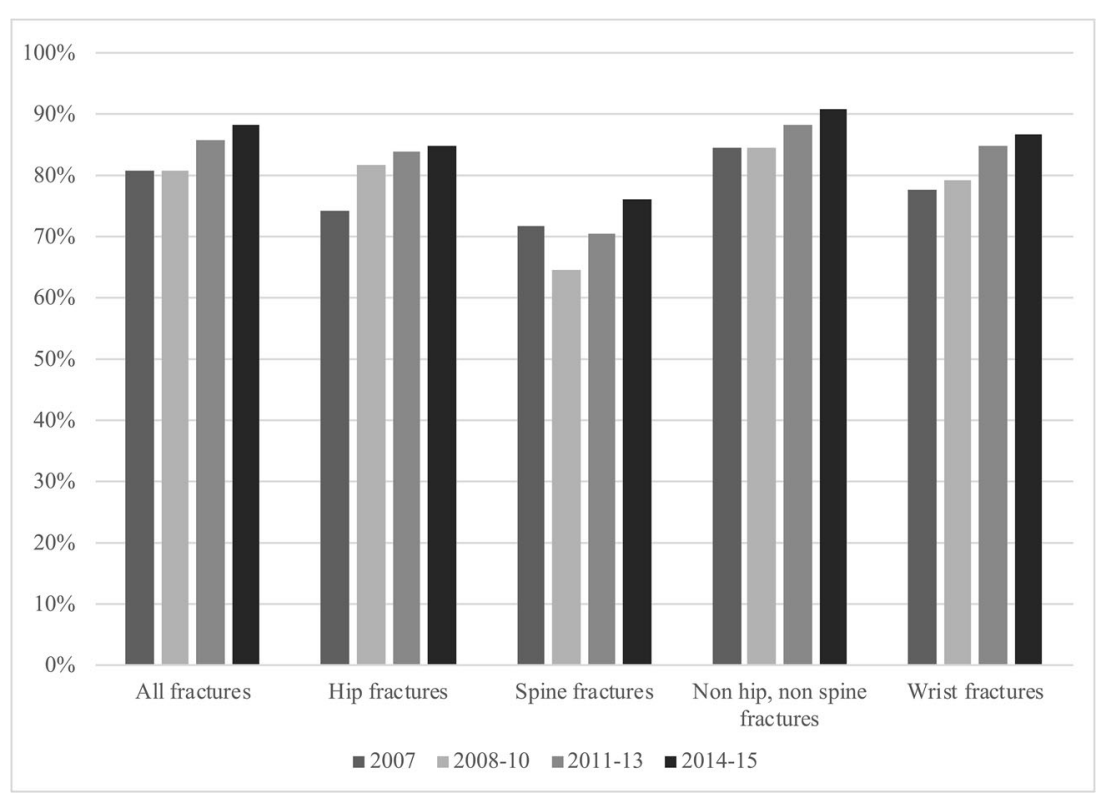

others demonstrate that the treatment gap seems to be a universal problem [23, 24, 30], also pertaining to European healthcare systems with a high level of access. Previous longitudinal studies have demonstrated an increasing treatment gap over time $[25,26]$, and while our study provides more recent data with significant differences between the UK, Catalonia, and Denmark, the overall impression is that the gap is stable or increasing in recent years. Hence, despite repeated calls for improved secondary fracture prevention on an international scale and improved availability of AOMincluding the emergence of new osteoporosis drugs with new characteristics that could widen patient acceptance of AOM as well as the availability of generic AOM-we have yet to see signs that this is improving. It deserves mentioning that a general trend towards a declining use of bisphosphonates, which has coincided with reports of rare or very rare adverse events as demonstrated by Jha et al. (2015), may contribute to the increasing treatment gap and hence wash out some of the effect of initiatives to improve secondary fracture prevention $[31,32]$. This trend was observed despite the fact that the absolute risk of such deleterious adverse events, notably atypical femur fractures, and osteonecrosis of the jaw, is very low $[32,33]$. Further, the International Osteoporosis Foundations Capture the Fracture programme was launched in 2012, coinciding with the smallest treatment gap in the UK in our analysis (during the 2011-13 time period), yet it is unlikely that our data reflects the full impact of a programme that has been expanding significantly since then.
Fig. 4 The treatment gap in Denmark stratified according to fracture location (all, hip, spine, non hip non spine, and wrist fractures, respectively) and time period

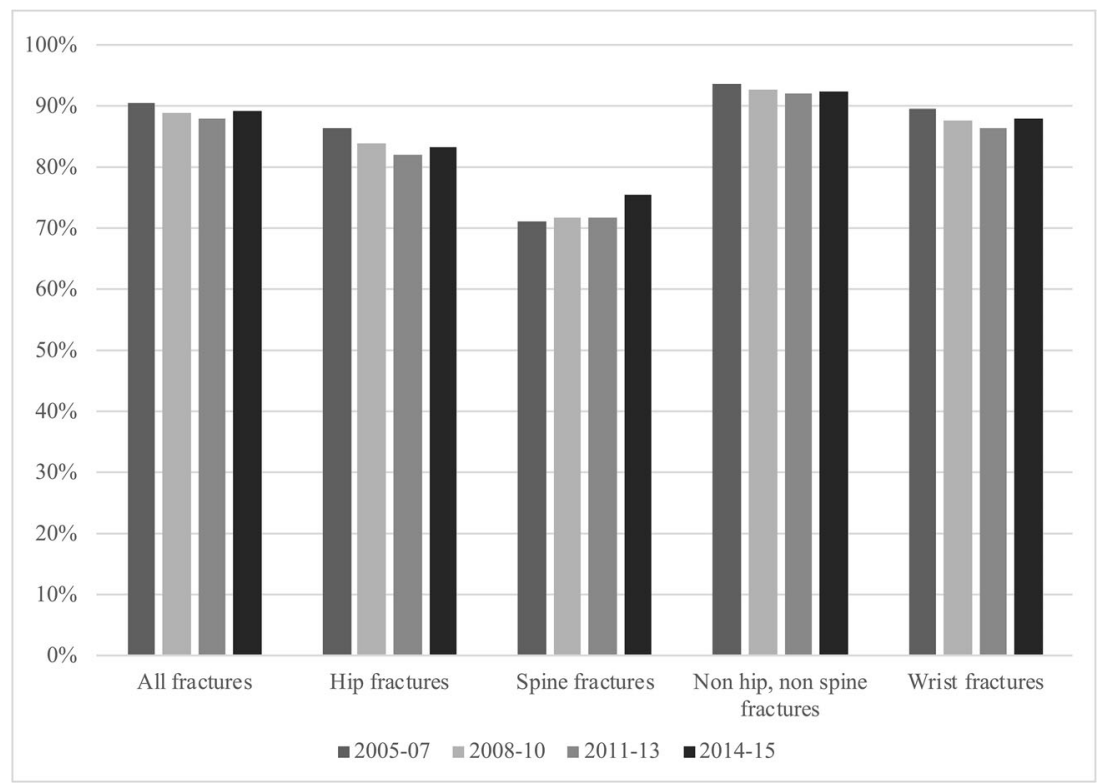




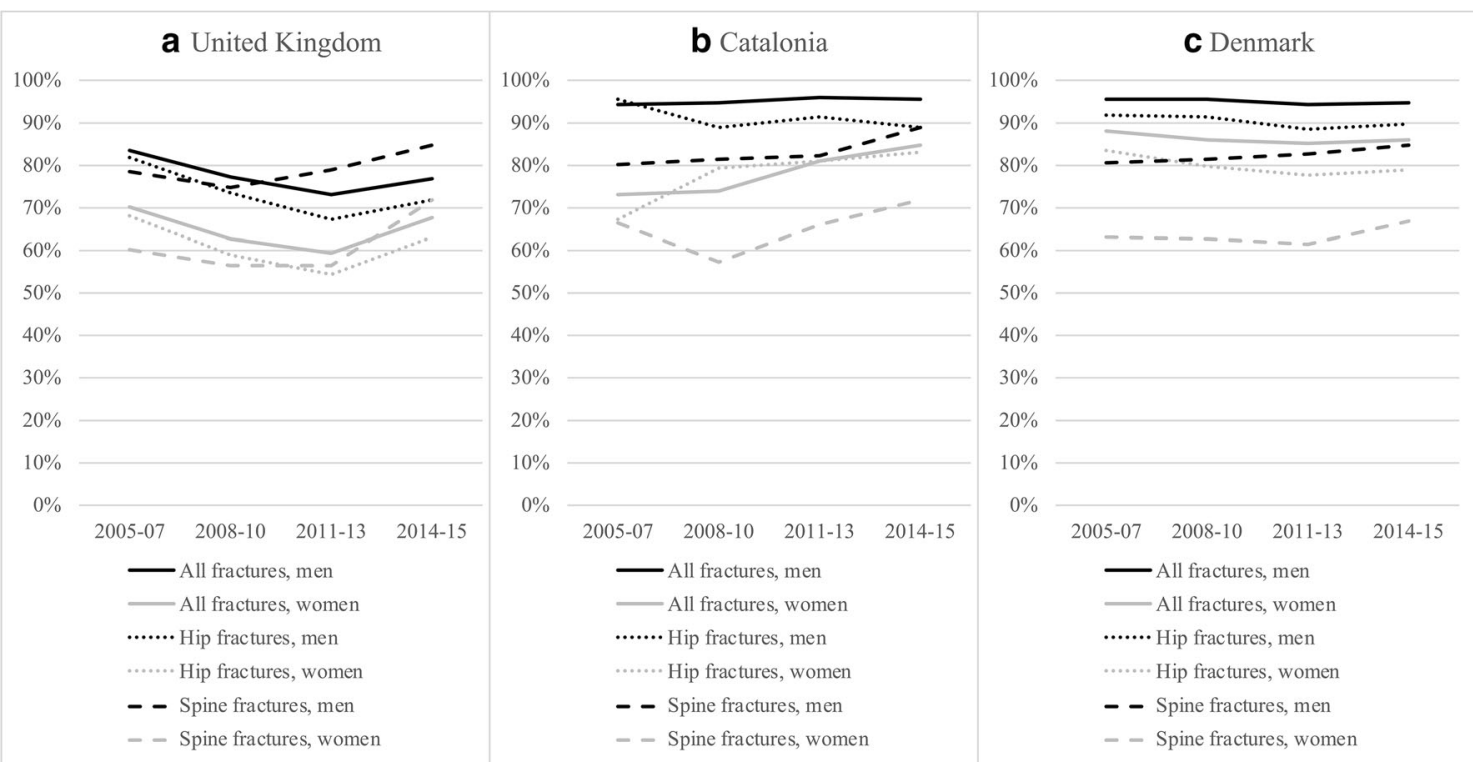

Fig. 5 The treatment gap in the United Kingdom (a), Catalonia (b), and Denmark (c), stratified according to time period, gender, and fracture location (all, hip, and spine, respectively)

Our analysis demonstrated significant differences in secondary fracture prevention between the geographic areas covered, with the UK achieving a substantially smaller treatment gap than Catalonia and, in particular, Denmark. As this study is based on administrative health databases, these differences may be reflective of underlying differences in data generation. Hence, in Denmark and Catalonia, patients are counted as ontreatment if they fill their prescriptions for AOM at the pharmacy, while in the UK, the patients are counted as ontreatment if they are prescribed an AOM. Patients with primary non-adherence would thus be counted in the CPRD as on treatment, while they would count as untreated in Denmark and Catalonia. This may cause an overestimation of the true adherence to osteoporosis guidelines in the UK. For comparison, a primary non-adherence rate of $20 \%$ has been calculated in SIDIAP, which beyond pharmacy dispensation data also holds prescription data like in the UK. Also, while the DHR is based on hospital data, CPRD and SIDIAP are based on primary care records linked to secondary care. This may explain some of the baseline differences, as primary care records generally tend to be more granular with regards to medical history as compared with secondary care records. Further, we predefined exclusion of patients with a lack of linkage to secondary care records, which has been suggested to account for $40 \%$ of CPRD practices and $70 \%$ of SIDIAP practices. This exclusion carries the risk of skewing the study population and may add to the differences in the treatment gap observed between the UK, Catalonia, and Denmark.

However, despite such potentially influencing factors, we believe that the national differences are, at least in part, indicative of more profound differences in secondary fracture prevention. These could reflect differences in access to care, yet all the countries in this study sustain a governmentfunded national healthcare system (although in Catalonia, co-payment policies was implemented in 2011, yet this does not seem to further fuel the increasing treatment gap), and, further, the Danish population did not appear to be significantly more impaired than the Catalan or UK populations, yet still demonstrated the poorest secondary fracture prevention. Another reason for the differences between the countries may be differences in national osteoporosis guidelines. While guidelines today seem to agree on the relevance of AOM therapy in patients with fragility fractures, as most recently evidenced by the ASBMR clinical recommendations (Conley et al., 2020) focusing on hip and vertebral fractures in patients aged 65 years or older $[14,15,18,33]$, UK guidelines have historically been less reliant on DXA-scans for the diagnosis of osteoporosis and thus for AOM treatment initiation than Danish or Spanish guidelines. This may have facilitated a smaller treatment gap in the UK in the early years of this analysis yet does not explain why the treatment gap persists in Denmark and Catalonia in recent years and increases towards the end of this study in the UK. We are not aware of evidence of diminishing use of DXA-scans in these countries, as has been demonstrated in the USA (coinciding with reduced reimbursement) [34].

Finally, differences in the healthcare system may affect the size of the treatment gap, in particular the implementation of care models for secondary prevention of fragility fractures. In a literature review, Ganda et al. (2013) demonstrated that fracture liaison services (FLS) are associated with significant improvements in BMD testing and treatment initiation in patients who have sustained a fragility fracture [35]. They found that increasing intensity of the FLS intervention was associated 
with greater effectiveness of the FLS and that the FLS is costeffective in daily clinical practice [35]. The UK began implementing FLS services systematically a decade ago. More recently, an FLS database for England and Wales was established under the auspices of the Royal College of Physicians, and this has captured data in real time since January 2016. It has been reported that in 2017, $43 \%$ of all fragility fractures were submitted to an FLS service [36]. Of these, $70 \%$ were assessed within 90 days of their fracture, and 43\% were recommended AOM treatment initiation [36]. Catalonia now has a relatively high number of accredited FLS services according to the IOF "Capture the Fracture" Map of Best Practice (www.capturethefracture.org) yet is still less comprehensively covered than the UK. Despite these reports being more recent than the study period covered in this paper, they point towards a higher level of attention towards secondary fracture prevention in Catalonia and, particularly, the UK. By contrast, fracture liaison services had not been systematically implemented in Denmark within the study period, and only three Danish hospitals now run an IOF "Capture the Fracture" accredited programme. This failure to provide follow-up services for fracture patients may contribute to the differences in the treatment gap observed between the three countries in this analysis.

An important aspect that needs to be kept in mind is that a $100 \%$ treatment rate would not necessarily be indicative of good clinical practice. Contraindications to the medications certainly exist and the benefit from treatment depends on life expectancy and the risk of side effects. In addition, patient preferences may also limit the number of patients that can be initiated on pharmacological therapy. To this end, the Royal College of Physicians introduced an FLS key performance indicator where $50 \%$ of patients should be initiated on pharmacological therapy [36]. This could be too low a target and benchmarking from secondary prevention in myocardial infarction; Leslie et al. (2012) argued that a pharmacological intervention target of $80 \%$ of patients with hip or spine fractures may in fact be more reasonable [37]. Irrespectively, the treatment gaps across the countries evaluated in this analysis are too large and require prompt addressing.

A limitation relevant to CPRD and SIDIAP is that we only capture those patients registered in the database and linked to hospital records. Both databases have been validated as representative of the national/regional population, yet, as significant proportions of the patients in CPRD and SIDIAP were excluded due to a lack of linkage to hospital records, there is a risk that our results may not be representative of the general population.

Another limitation is that use of zoledronic acid and denosumab are not regularly reflected in CPRD for this time period, while in Denmark hospital-administered zoledronic acid is not reflected in the National Prescription Registry. This may cause an underestimation of the treatment rate.
Our study has a number of strengths including the large number of patients and fractures evaluated, the robustness of the methodology, and the use of validated databases.

In conclusion, this study provides long-term, comparative data regarding the treatment gap after an incident osteoporotic fracture among patients from the UK, Catalonia, and Denmark. We have demonstrated that despite repeated calls for improved pharmacological secondary prevention, an unacceptably large treatment gap still exist, more pronounced in men than in women. Differences in the treatment gap are evident across the countries evaluated in our analysis, possibly arguing in favour of the effectiveness of structural healthcare interventions. Regardless, our study highlights that additional efforts to reduce the treatment gap are highly and urgently needed.

Funding information UCB funded this study. All analyses were conducted independently by the academic researchers involved. MKJ is supported by the National Institute for Health Research (NIHR) Oxford Biomedical Research Centre (BRC).

\section{Compliance with ethical standards}

The study protocol was approved by the ISAC ethics committee for use of CPRD data, by the SIDIAP Scientific and Ethics Committee, and for the use of the Danish Health Registries by the Danish Medicines Agency, the Danish Data Protection Agency and Statistics Denmark.

For this type of study, formal consent is not required.

Conflicts of interest MKS has institutional research contract with UCB and educational grant from UCB. SK has nothing to disclose. ME has institutional research contract with UCB. KHR has nothing to disclose. DML received personal fees from Amgen, Eli Lilly, Novartis, Ferrer, and Rubió. AD reports grants from UCB during the conduct of the study. MKJ received honoraria, unrestricted research grants, and travel and/or subsistence expenses from Amgen and UCB. CC received personal fees from Alliance for Better Bone Health, Amgen, Eli Lilly, GSK, Medtronic, Merck, Novartis, Pfizer, Roche, Servier, Takeda, and UCB. CL and ET are employees of UCB Pharma. BA has institutional research contracts with Novartis and UCB with funds paid to the institution and received speaker fees from Amgen and personal consultancy fees from UCB and Kyowa-Kirin UK. DPA received institutional research grants from UCB and Amgen, grant from Les Laboratoires Servier, educational grants from Johnson \& Johnson, and speaker and consultancy fees paid to his department by Amgen and UCB. Janssen, on behalf of IMI-funded EHDEN and EMIF consortiums, and Synapse Management Partners have supported training programmes organized by DPA's department and open for external participants.

Open Access This article is licensed under a Creative Commons Attribution-NonCommercial 4.0 International License, which permits any non-commercial use, sharing, adaptation, distribution and reproduction in any medium or format, as long as you give appropriate credit to the original author(s) and the source, provide a link to the Creative Commons licence, and indicate if changes were made. The images or other third party material in this article are included in the article's Creative Commons licence, unless indicated otherwise in a credit line to the material. If material is not included in the article's Creative Commons licence and your intended use is not permitted by statutory regulation or exceeds the permitted use, you will need to obtain permission directly from the copyright holder. To view a copy of this licence, visit http://creativecommons.org/licenses/by-nc/4.0/. 


\section{References}

1. Hernlund E, Svedbom A, Ivergård M et al (2013) Osteoporosis in the European Union: medical management, epidemiology and economic burden: a report prepared in collaboration with the international Osteoporosis Foundation (IOF) and the European Federation of Pharmaceutical Industry Associations (EFPIA). Arch Osteoporos 8:1-115. https://doi.org/10.1007/s11657-013-0136-1

2. Klotzbuecher CM, Ross PD, Landsman PB, Abbott TA 3rd, Berger $M$ (2000) Patients with prior fractures have an increased risk of future fractures: a summary of the literature and statistical synthesis. J Bone Miner Res 15:721-739. https://doi.org/10.1359/jbmr.2000. 15.4.721

3. Kanis JA, Johnell O, De Laet C et al (2004) A meta-analysis of previous fracture and subsequent fracture risk. Bone 35:375-382. https://doi.org/10.1016/j.bone.2004.03.024

4. Van Geel T, Van Helden S, Geusens P et al (2009) Clinical subsequent fractures cluster in time after first fractures. Ann Rheum Dis 68:99-102. https://doi.org/10.1136/ard.2008.092775

5. Wells GA, Cranney A, Peterson J et al (2008) Alendronate for the primary and secondary prevention of osteoporotic fractures in postmenopausal women. Cochrane Database Syst Rev. https://doi.org/ 10.1002/14651858.CD001155.pub2

6. Wells GA, Cranney A, Peterson J et al (2008) Risedronate for the primary and secondary prevention of osteoporotic fractures in postmenopausal women. Cochrane Database Syst Rev. https://doi.org/ 10.1002/14651858.CD004523.pub3

7. Wells GA, Cranney A, Peterson J et al (2008) Etidronate for the primary and secondary prevention of osteoporotic fractures in postmenopausal women. Cochrane Database Syst Rev:1-77. https:// doi.org/10.1002/14651858.CD003376.pub3

8. Harvey NC, McCloskey EV, Mitchell PJ et al (2017) Mind the (treatment) gap: a global perspective on current and future strategies for prevention of fragility fractures. Osteoporos Int 28:1507-1529. https://doi.org/10.1007/s00198-016-3894-y

9. Lyles KW, Colón-Emeric CS, Magaziner JS, Adachi JD, Pieper CF, Mautalen C, Hyldstrup L, Recknor C, Nordsletten L, Moore KA, Lavecchia C, Zhang J, Mesenbrink P, Hodgson PK, Abrams K, Orloff JJ, Horowitz Z, Eriksen EF, Boonen S, HORIZON Recurrent Fracture Trial (2007) Zoledronic acid and clinical fractures and mortality after hip fracture. N Engl J Med 357:17991809. https://doi.org/10.1056/NEJMoa074941

10. Ettinger B, Black D, Mitlak B, Knickerbocker RK, Nickelsen T, Genant HK, Christiansen C, Delmas PD, Zanchetta JR, Stakkestad J, Glüer CC, Krueger K, Cohen FJ, Eckert S, Ensrud KE, Avioli LV, Lips P, Cummings SR (1999) Reduction of vertebral fracture risk in postmenopausal women with osteoporosis treated with raloxifene: results from a 3-year randomized clinical trial. JAMA 282:637-645

11. Neer RM, Arnaud CD, Zanchetta JR, Prince R, Gaich GA, Reginster JY, Hodsman AB, Eriksen EF, Ish-Shalom S, Genant HK, Wang O, Mitlak BH (2001) Effect of parathyroid hormone (1-34) on fractures and bone mineral density in postmenopausal women with osteoporosis. N Engl J Med 344:1434-1441. https:// doi.org/10.1056/NEJM200105103441904

12. Meunier PJ, Roux C, Seeman E, Ortolani S, Badurski JE, Spector TD, Cannata J, Balogh A, Lemmel EM, Pors-Nielsen S, Rizzoli R, Genant HK, Reginster JY (2004) The effects of strontium ranelate on the risk of vertebral fracture in women with postmenopausal osteoporosis. N Engl J Med 350:459-468. https://doi.org/10.1056/ NEJMoa022436

13. Palacios S, Kalouche-Khalil L, Rizzoli R, Zapalowski C, Resch H, Adachi JD, Gallagher JC, Feldman RG, Kendler DL, Wang A, Wagman RB, Adami S (2015) Treatment with denosumab reduces secondary fracture risk in women with postmenopausal osteoporosis. Climacteric 18:805-812. https://doi.org/10.3109/ 13697137.2015.1045484

14. Nielsen MF, Harsløf T, Kvist T, et al (2016) National Behandlingsvejledning: Osteoporose. Dansk Endokrinologisk Selskab. http://www.endocrinology.dk/index.php/3-calcium-ogknoglemetaboliske-sygdomme/3-osteoporose

15. National Osteoporosis Guideline Group (2017) NOGG 2017: Clinical guideline for the prevention and treatment of osteoporosis. https://www.sheffield.ac.uk/NOGG/NOGGGuideline2017.pdf

16. Cooper C, Ferrari S, IOF Board and Executive Committee (2017) IOF Compendium of Osteoporosis. International Osteoporosis Foundation. http://share.iofbonehealth.org/WOD/Compendium/ IOF-Compendium-of-Osteoporosis-WEB.pdf

17. Kanis J, Cooper C, Rizzoli R, Reginster JY (2019) Scientific Advisory Board of the European Society for Clinical and Economic Aspects of Osteoporosis (ESCEO) and the Committees of Scientific Advisors and National Societies of the International Osteoporosis Foundation (IOF). European guidance for the diagnosis and management of osteoporosis in postmenopausal women. Osteoporos Int 30:3-44. https://doi.org/10.1007/s00198-0184704-5

18. González-Macías J, del Pino-Montes J, Olmos JM et al (2015) Clinical practice guidelines for postmenopausal, glucocorticoidinduced and male osteoporosis. Spanish Society for Research on Bone and Mineral Metabolism (3rd updated version 2014). Rev Clin Esp 215:515-526. https://doi.org/10.1016/j.rceng.2015.08. 005

19. Papaioannou A, Giangregorio L, Kvern B et al (2004) The osteoporosis care gap in Canada. BMC Musculoskelet Disord 5:1-6. https://doi.org/10.1186/1471-2474-5-11

20. Papaioannou A, Kennedy CC, Ioannidis G, Gao Y, Sawka AM, Goltzman D, Tenenhouse A, Pickard L, Olszynski WP, Davison KS, Kaiser S, Josse RG, Kreiger N, Hanley DA, Prior JC, Brown JP, Anastassiades T, Adachi JD, CaMos Research Group (2008) The osteoporosis care gap in men with fragility fractures: the Canadian Multicentre Osteoporosis Study. Osteoporos Int 19: 581-587. https://doi.org/10.1007/s00198-007-0483-0

21. Fraser LA, Ioannidis G, Adachi JD, Pickard L, Kaiser SM, Prior J, Brown JP, Hanley DA, Olszynski WP, Anastassiades T, Jamal S, Josse R, Goltzman D, Papaioannou A, CaMos Research Group (2011) Fragility fractures and the osteoporosis care gap in women: the Canadian Multicentre Osteoporosis Study. Osteoporos Int 22: 789-796. https://doi.org/10.1007/s00198-010-1359-2

22. Wilk A, Sajjan S, Modi A, Fan CP, Mavros P (2014) Post-fracture pharmacotherapy for women with osteoporotic fracture: analysis of a managed care population in the USA. Osteoporos Int 25:27772786. https://doi.org/10.1007/s00198-014-2827-x

23. Kim TI, Choi JH, Kim SH, Oh JH (2016) The adequacy of diagnosis and treatment for osteoporosis in patients with proximal humeral fractures. Clin Orthop Surg 8:274-279. https://doi.org/10. 4055/cios.2016.8.3.274

24. Cheung M, Ho AW, Wong S (2018) Post-fracture care gap: a retrospective population-based analysis of Hong Kong from 2009 to 2012. Hong Kong Med J 24:579-583. https://doi.org/10.12809/ hkmj187227

25. Barton DW, Behrend CJ, Carmouche JJ (2019) Rates of osteoporosis screening and treatment following vertebral fracture. Spine J 19:411-417. https://doi.org/10.1016/j.spinee.2018.08.004

26. Leslie WD, Giangregorio LM, Yogendran M, Azimaee M, Morin S, Metge C, Caetano P, Lix LM (2012) A population-based analysis of the post-fracture care gap 1996-2008: the situation is not improving. Osteoporos Int 23:1623-1629. https://doi.org/10.1007/s00198011-1630-1

27. International Osteoporosis Foundation (2018) Broken bones, broken lives: a roadmap to solve the fragility fracture crisis in Europe. 
International Osteoporosis Foundation. http://share.iofbonehealth. org/EU-6-Material/Reports/IOF\%20Report_EU.pdf

28. Nguyen ET, Posas-Mendoza T, Siu AM, Ahn HJ, Choi SY, Lim SY (2018) Low rates of osteoporosis treatment after hospitalization for hip fracture in Hawaii. Osteoporos Int 29:1827-1832. https://doi. org/10.1007/s00198-018-4553-2

29. Giangregorio L, Papaioannou A, Cranney A, Zytaruk N, Adachi JD (2006) Fragility fractures and the osteoporosis care gap: an international phenomenon. Semin Arthritis Rheum 35:293-305. https:// doi.org/10.1016/j.semarthrit.2005.11.001

30. Mendis AS, Ganda K, Seibel MJ (2017) Barriers to secondary fracture prevention in primary care. Osteoporos Int 28:29132919. https://doi.org/10.1007/s00198-017-4131-z

31. Jha S, Wang Z, Laucis N, Bhattacharyya T (2015) Trends in media reports, oral bisphosphonate prescriptions, and hip fractures 19962012: an ecological analysis. J Bone Miner Res 30:2179-2187. https://doi.org/10.1002/jbmr.2565

32. Black DM, Abrahamsen B, Bouxsein ML, Einhorn T, Napoli N (2019) Atypical femur fractures: review of epidemiology, relationship to bisphosphonates, prevention, and clinical management. Endocr Rev 40:333-368. https://doi.org/10.1210/er.2018-00001

33. Conley RB, Adib G, Adler RA et al (2020) Secondary fracture prevention: consensus clinical recommendations from a multistakeholder coalition. J Bone Miner Res 35:36-52. https:// doi.org/10.1002/jbmr.3877

34. Overman RA, Farley JF, Curtis JR, Zhang J, Gourlay ML, Deal CL (2015) DXA utilization between 2006 and 2012 in commercially insured younger postmenopausal women. J Clin Densitom 18:145149. https://doi.org/10.1016/j.jocd.2015.01.005

35. Ganda K, Puech M, Chen J et al (2013) Models of care for the secondary prevention of osteoporotic fractures: a systematic review and meta-analysis. Osteoporos Int 24:393-406. https://doi.org/10. 1007/s00198-012-2090-y

36. Royal College of Physicians (2018) Secondary fracture prevention in the NHS: Achieving effective service delivery by FLSs. London: RCP, 2018 https://www.fffap.org.uk/fls/flsweb.nsf/FLS-Rep_2018. pdf

37. Leslie WD, LaBine L, Klassen P et al (2012) Closing the gap in postfracture care at the population level: a randomized controlled trial. Can Med Assoc J 184:290-296. https://doi.org/10.1503/cmaj. 111158

Publisher's note Springer Nature remains neutral with regard to jurisdictional claims in published maps and institutional affiliations. 